\title{
A path convergence theorem and construction of fixed points for nonexpansive mappings in certain Banach spaces
}

\section{T. M. M. Sow, N. DjitTe and C.E. Chidume}

\section{ABSTRACT.}

In this paper, we introduce a new iterative process to approximate fixed points of nonexpansive maps in real Banach spaces having weakly continuous duality map and establish strong convergence theorems for the proposed iterative process. There is no compactness assumption on $K$ or on $T$. Our results improve important recent results.

Acknowledgements. The first author is supported by The Center of Exellence CEAMITIC, Gaston Berger University, Senegal.

The authors thank the referees for their work and their valuable suggestions that helped to improve the presentation of this paper.

\section{REFERENCES}

[1] Berinde, V., Iterative approximation of fixed points, Lecture Notes in Mathematics, 1912 (2007), ISBN-10 3-54072233-5, Springer, Berlin, Heildelberg, New York

[2] Browder, F. E., Convergenge theorem for sequence of nonlinear operator in Banach spaces, Math. Z., 100 (1967) 201-225

[3] Browder, F. E., Convergence of approximants to fixed points of nonexpansive nonlinear mappings in Banach spaces, Arch. Rational Mech. Anal., 24 (1967), 82-90

[4] Byrne, C., A unified treatment of some iterative algorithms in signal processing and image restoration, Inverse Problems, 20 (2004), 103-120

[5] Chidume, Ch., Geometric Properties of Banach spaces and Nonlinear Iterations, Springer Verlag, Series: Lecture Notes in Mathematics, Vol. 1965 (2009), ISBN 978-1-84882-189-7

[6] Chidume, C. E., On the approximation of fixed points of nonexpansive mappings, Houston J. Math., 7 (1981), 345-355

[7] Cho, Y. J., Kang, S. M. and Zhou, H. Y., Some control conditions on iteratives methods, Comm. Appl. Nonlinear Anal., 12 (2005), No. 2, 27-34

[8] Ciorănescu, I., Geometry of Banach spaces, duality mappings and nonlinear problems. Mathematics and its Applications, 62, Kluwer Academic Publishers Group, Dordrecht, 1990. xiv+260 pp.

[9] Edelstein, M. and O'Brian, R. C., Nonexpansive mappings, asymptotic regularity and successive approximations, J. London Math. Soc., 17 (1978), No. 3, 547-554

[10] Genel, A. and Lindenstrass, J., An example concerning fixed points, Israel J. Math., 22 (1975), No. 1, 81-86

[11] Goebel, K. and Kirk, W. A., Topics in metric fixed poit theory, Cambridge Studies, in Advanced Mathemathics, 28, University Cambridge Press, Cambridge 1990

[12] Halpern, B., Fixed points of nonexpansive maps, Bull. Amer. Math. Soc., 3 (1967), 957-961

[13] Ishikawa, S., Fixed points and iteration of nonexpansive mapping in a Banach space, Proc. Amer. Math. Soc., 73 (1976), 61-71

[14] Krasnosel'skiü, M. A., Two observations about the method of successive approximations, Uspehi Math. Nauk, 10 (1955), 123-127

[15] Kirk, W. A., Locally nonexpansive mappings in Banach spaces, pp. 178-198, Lecture Notes in Math., 886, Springer-Verlag, Berlin, 1981

Received: 09.03.2015; In revised form: 18.11.2015; Accepted: 25.11.2015

2010 Mathematics Subject Classification. 47H04, 47H06, 47H15, 47H17, 47J25.

Key words and phrases. Fixed point, reflexive Banach spaces, weakly continuous duality maps.

Corresponding author: Ngalla Djitte; ngalla.djitte@ugb.edu.sn 
[16] Lions, P. L., Approximation de points fixed de contractions, C. R. Acad. Sci. Paris Ser. A, 284 (1977), 1357-1359

[17] Mann, W. R, Mean value methods in iteration, Proc. Amer. Math. Soc., 4 (1953), 506-510

[18] Opial, Z., 23'Weak convergence of sequence of succecive approximation of nonexpansive mapping', Bull. Am. Math. Soc., 73 (1967), 591-597

[19] Reich, S., Approximating fixed points of nonexpansive mappings, Panamer. Math. J., 4 (1994), No. 2, 23-28

[20] Reich, S., Some problems and results in fixed point theory, Contemp. Math., 21 (1983), 179-187

[21] Reich, S., Strong convergent theorems for resolvents of accretive operators in Banach spaces, J. Math. Anal. Appl., 75 (1980), 287-292

[22] Schaefer, H., Uber die Methode sukzessiver Approximationen, (German) Jber. Deutsch. Math. Verein., 59 (1957), Abt. 1, 131-140

[23] Shioji, S. and Takahashi, W., Strong convergence of approximated sequences for nonexpansive mappings in Banach spaces, Proc. Amer. Math. Soc., 125 (1997), 3641-3645

[24] Takahashi, W. and Ueda, Y., On Reich's strong convergence theorems for resolvents of accretive operators, J. Math. Anal. Appl., 104 (1984), No. 2, 546-553

[25] Wittmann, R., Approximation of fixed points of nonexpansive mappings, Arch. Math., 58 (1992), 486-491

[26] Xu, H. K., Iterative algorithms for nonlinear operators, J. London Math. Soc. (2), 66 (2002), No. 1, 240-256

\author{
DePARTMENT MATHEMATICS \\ GASTON BERGER UNIVERSITY \\ BP 234, SAINT LOUIS, SENEGAL \\ E-mail address: sowthierno89@gmail.com \\ E-mail address: ngalla.djitte@ugb.edu.sn \\ DePARTMENT MATHEMATICS \\ AFRICAN UNIVERSITY OF SCIENCES AND TECHNOLOGY \\ ABUJA, NigERIA \\ E-mail address: cchidume@aust. edu.ng
}

